\title{
A WAY TO PREDICT NATURAL HAZARDS IN KARST
}

\section{Pierre-Yves Jeannin}

Swiss Institute for Speleology and Karst-Studies, SISKA, Serre 68, CH-2301 La Chaux-de-Fonds, pierre-yves.jeannin@isska.ch

\section{Arnauld Malard}

Swiss Institute for Speleology and Karst-Studies, SISKA, Serre 68, CH-2301 La Chaux-de-Fonds, arnauld.malard@isska.ch

\begin{abstract}
Flooding, ground collapses, subsidence and contamination are hazards often encountered in a karst environment. All are strongly associated to water. A good knowledge of the distribution of groundwater potentiometric heads and fluxes in space and time is necessary to predict and prevent these hazards.
\end{abstract}

A series of karst-specific approaches are being developed by SISKA (Swiss Institute for Speleology and KarstStudies) in order to provide this type of information within a reasonable effort. Most of these are based on a key-approach (KARSYS) and could be successively applied to address issues in karst environment. Applications for flood and sinkhole hazards are presented. These approaches are organized in a "Karst toolbox" which is being developed first and mainly for karst in temperate and mountainous regions (as we have in central Europe). Adjustments and extensions for other contexts (e.g. lowland karst or hypogenic karst areas) could be developed.

\section{Introduction}

The most frequent hazards in karst environment are flooding, ground collapse, subsidence and groundwater contamination. If water is the key factor for flooding and contamination, it may appear a little less direct for ground collapse and subsidence. However, when looking at the literature (e.g. Waltham et al., 2005) it turns out that most ground collapses and dolines are produced by changes in groundwater conditions, especially when the groundwater table is located within unconsolidated sediments covering the karstified rock.

Therefore a key issue concerning hazards is to characterize groundwater heads and fluxes under low to high flow conditions. Ideally karst hydrogeologists would like to know hydraulic heads and fluxes anywhere in the karst aquifer, i.e. have a clear image of groundwater flow systems and their variations in time!

Many studies are however mainly focused either on the temporal (e.g. time series analyses) or spatial (e.g. positioning of a drillhole) aspects. Usually, quantitative modelling approaches are applied to link both aspects together, but they require a huge effort, and are thus mostly reserved to academic work.

In most situations, a qualitative "conceptual 3D spatial model" of the groundwater flow-system is sufficient to address practical questions, as long as the model provides local information over the whole investigated region, not just a generalized scheme (e.g. a hydrogeological cross-section) as observed in many studies.

Here we present an approach for synthesizing all available data into such a conceptual 3D spatial model. We believe that this type of approach is more efficient for addressing practical questions such as ground collapses or flooding than classical groundwater flow modelling, which is highly time consuming and still contains a high uncertainty.

\section{Approach}

Over the past 10 years a series of practical approaches have been developed at SISKA to characterize karst flow systems. This "karst toolbox" is sketched on Figure 1, and the main approaches are briefly described hereafter. The assessment of hazards, such as floods (Number 5 on Figure 1) and karstic collapse (Number 7 on Figure 1), requires the application of most of these approaches sequentially.

KARSYS is the keystone of this toolbox. It provides an explicit model of the groundwater flow system, based on a 3D geological model of the karst aquifer (Figure 2). To construct the model, all existing geological data (geological map, cross-sections, borehole, etc.) are gathered and interpreted to describe the geometry of the karst aquifer. Then, hydrological data such as springs, swallow-holes, estavelles, water-levels in caves, or boreholes are introduced explicitly into the 3D geological model. The data are then interpolated according to two fundamental hydraulic principles: 1) hydraulic gradient is low in karst aquifers (close to zero, at least in low water situation) due to the high hydraulic conductivity of karst channels; 2) the hydraulic gradient is vertical in the unsaturated zone, meaning that flow is 


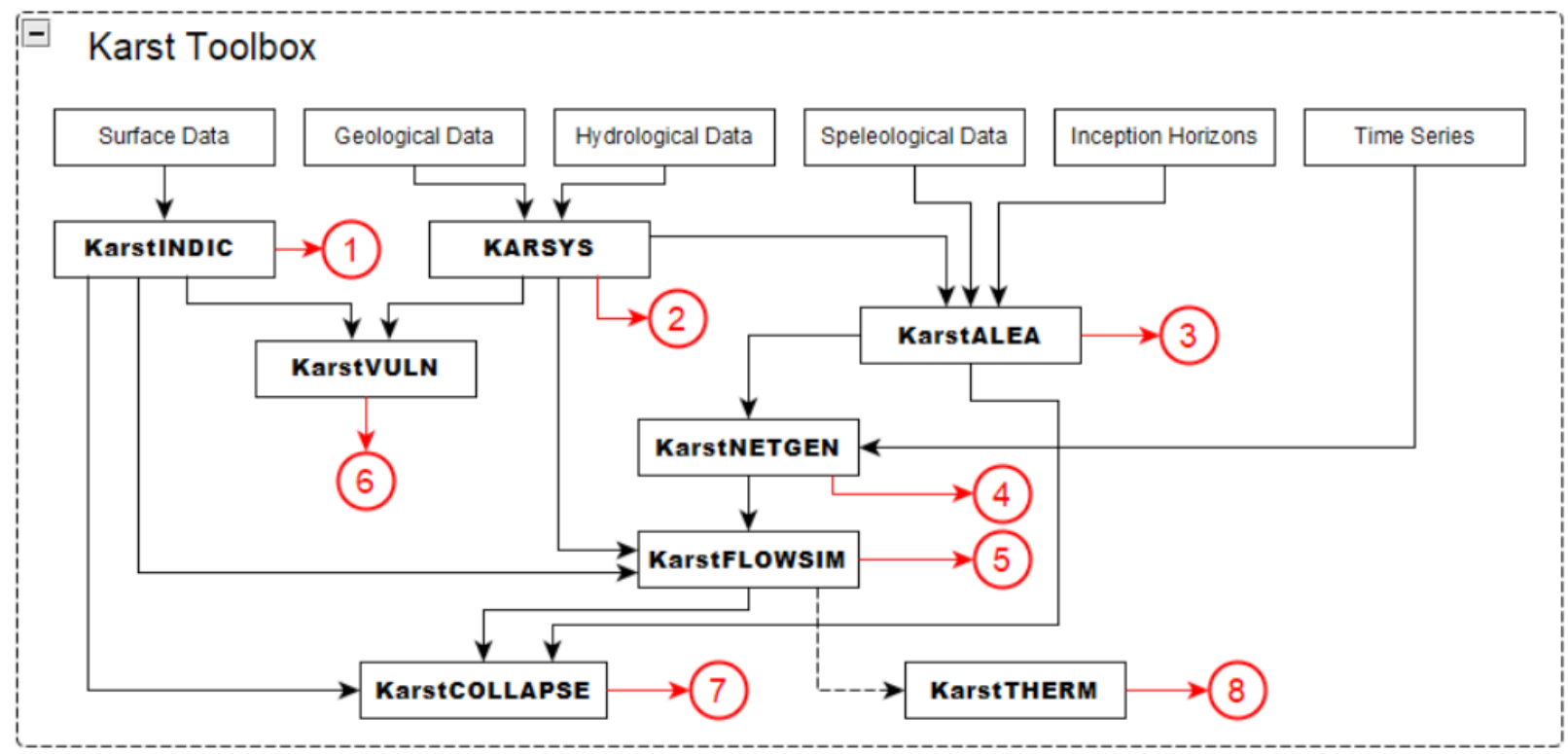

OUTPUTS:

(1) Maps of karst characteristics at ground surface

(2) 3D model of karst aquifer, catchment delineation

(3) Prediction of karst occurences for underground construction

(4) Prediction of the expected karst channels network

(5) Simulation of recharge / discharge, and 3D field of heads and fluxes -> flood hazards assessment

6) Vulnerability maps, and protection zones

(7) Collapses hazard maps

(8) Dimensioning of geothermal probes in karst

Figure 1. Sketch of the "Karst Toolbox" showing methods leading to the various outputs (red numbers). KARSYS and KarstINDIC are the first steps, making possible to assess groundwater vulnerability to contamination (KarstVULN). KarstALEA takes the genesis of karst into consideration, making possible to assess the position and characteristics of karst features. It can be used to generate a network of karst conduits (KarstNETGEN), which in turn can be used for groundwater flow simulation (KarstFLOWSIM). This can be used for flood assessment (5). KarstCOLLAPSE makes possible to predict ground collapses by combining results of KarstINDIC, KarstFLOWSIM and KarstALEA mainly.

vertical or down-dip along the top of impervious layers. The modeler can thus produce a 3D scene of his vision of groundwater flows according to his knowledge of the aquifer and data. The resulting KARSYS model then provides maps of the saturated and confined zones, the main drainage axes, the expected groundwater heads, and the catchment area related to a spring or a group of springs.

KarstINDIC (Figure 3) aims at characterizing conditions of water infiltration, as well as to map the main morphological features which are significant for groundwater and the preservation of natural heritage.
KarstINDIC is a mapping procedure of karst features which are visible at land surface. Most data can be extracted from geological maps, geomorphological maps, aerial photos, digital elevation models, cave inventories, etc. Field observations can be added for improving the liability and precision, but are not systematically required. KarstINDIC is a necessary step for hazard assessment for which water infiltration is a key parameter.

KarstALEA (Figure 4) was developed for predicting karst occurrences in tunneling (Filipponi et al. 2012), and is recognized as an official method for assessing karst 


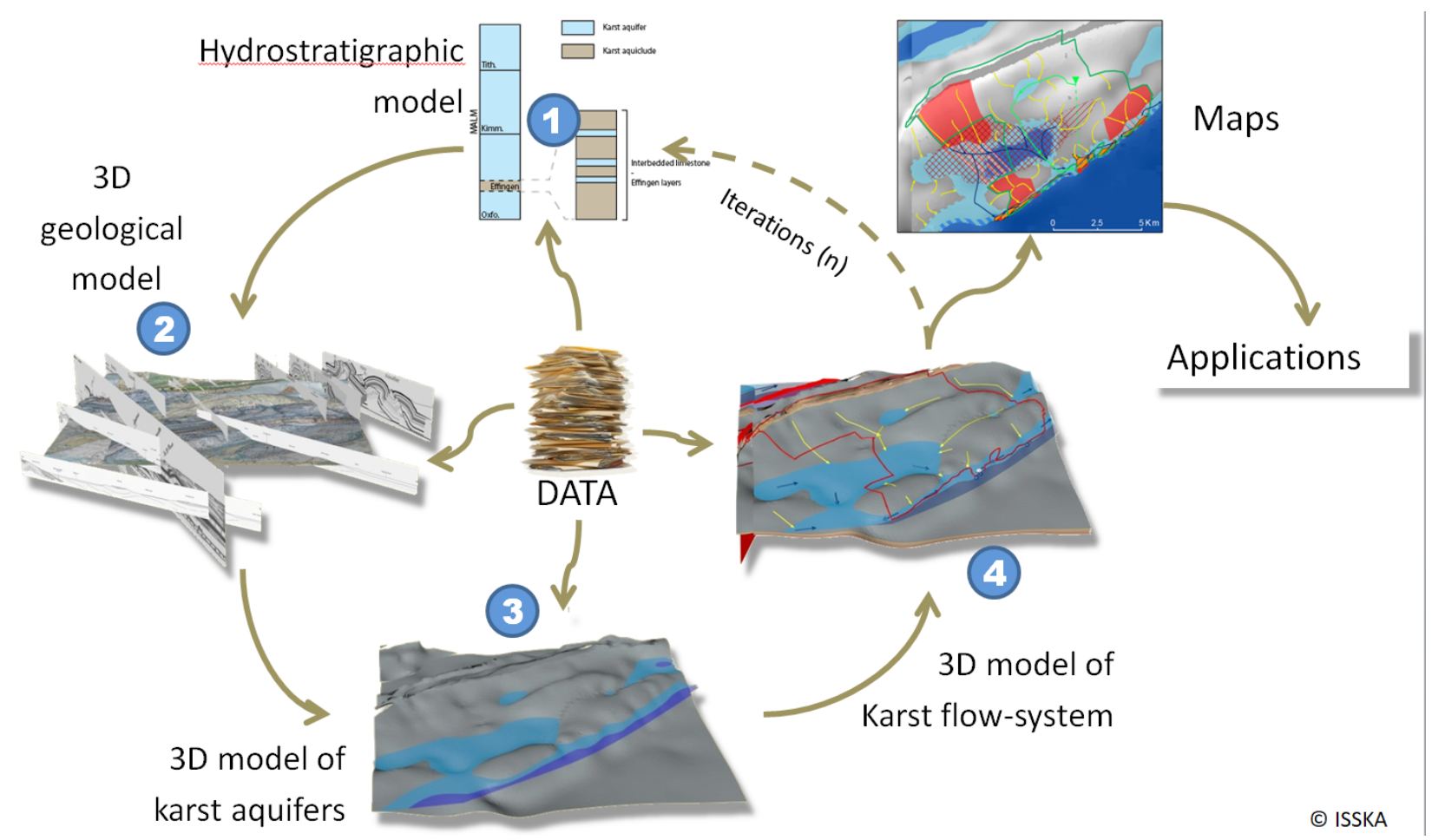

Figure 2. Steps and outputs of the KARSYS approach. 1) The modeler identifies karstified rocks (aquifer) and aquicludes based on geological data (hydrostratigraphic model). 2) A 3D geological model of the karstified rocks and aquicludes is built. 3) Hydrological information is added to the 3D geological model and a model of the karst aquifer is produced. 4) By applying some rules of the hydraulics of flow in karst, the groundwater flow system can be created explicitly. Finally maps and other outputting information can be produced for dedicated applications (e.g. groundwater resource assessment).

by Swiss civil engineers. A model of the speleogenetical conditions and inception horizons are added to the KARSYS model, making possible to predict the potential position of karst channels as well as their characteristics (expected size, shape, infilling, etc.). It can be applied to any type of underground construction in karst. The method can also be applied to the near-surface to identify the potential location of sinkholes. However, KarstALEA alone is not sufficient as most sinkholes are related to the collapse of unconsolidated sediments covering karstified rock (e.g. soils, tills or loess). Therefore, characteristics of the cover must be considered, as well as hydrologic conditions within the sediments.

KarstNETGEN (Figure 5) is being developed to generate karst conduit networks within the 3D geological model, considering probabilities inferred in the KarstALEA model. Compared to other models, it specifically accounts for the spatial distribution of recharge (zones of diffuse or discrete recharge), speleological zones and inception horizons. Details of this model are presented in Malard et al. (2015).
KarstFLOWSIM is being developed to simulate both heads and flow in a karst aquifer. Various levels of details can be used in KarstFLOWSIM, requiring a more or less precise description of the karst conduit network. The first level aims at simulating hydrographs (time series of discharge rate) of the whole flow-system. This simulation process includes the assessment of effective recharge into the aquifer. A second level can be achieved by introducing the hydraulics of flow (in using for example InfoWork (C) or SWMM()) in a partially saturated pipe network generated with KarstNETGEN. If necessary, flow and heads in the rock matrix between the karst channels can be simulated using results of the hydraulics of the conduit network. Most steps of KarstFLOWSIM have already been applied to practical cases (e.g. Jeannin et al. 2015). An example is presented in Figure 6. KarstFLOWSIM is permanently developed in order to improve its applicability: For example, a KarstFLOOD module is being developed according to some criteria, such as flooding probability classes (Vouillamoz et al. 2013). 


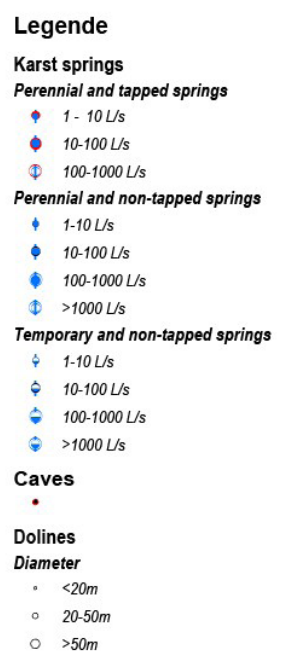

Lapiaz
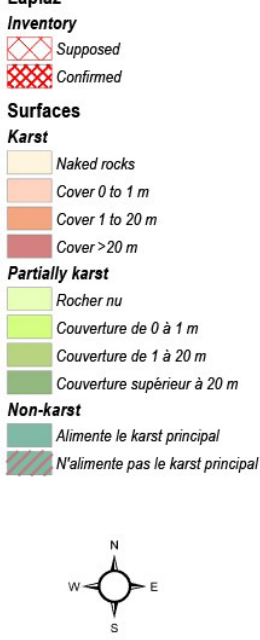

$\begin{array}{lll}0 & 0.25 & 0.5\end{array}$

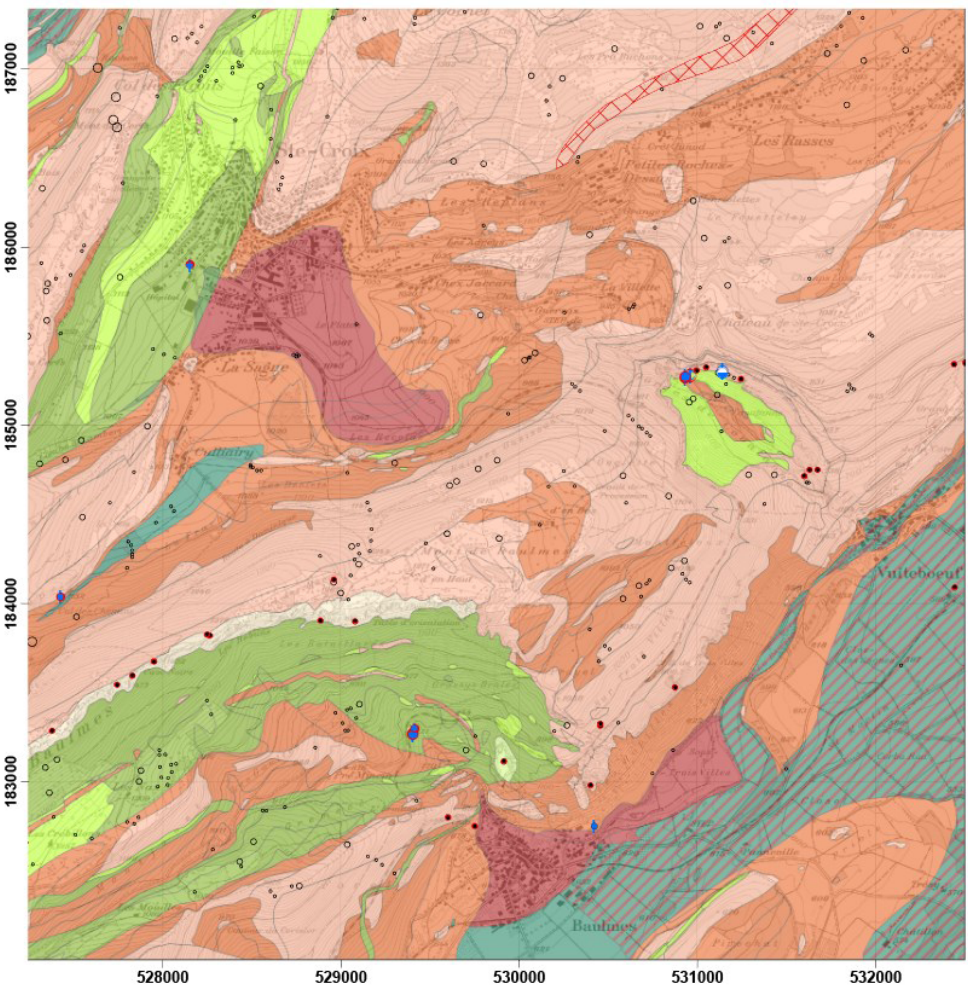

Figure 3. Example of a KarstINDIC map representing karst features controlling water infiltration, and providing indications about patrimonial issues.

Finally, KarstVULN and KarstCOLLAPSE are the next modules to be developed. The goal of KarstVULN is to produce vulnerability maps showing regions where groundwater is more vulnerable to contamination for surface pollutants. These maps can then be used to delineate groundwater protection zones according to water protection laws proper to each country. For these maps information of KarstINDIC and KARSYS will be combined based on a revised version of the EPIK method (Doerfliger et al. 1999), which is being prepared under the direction of the Swiss Office for the Environment.

KarstCOLLAPSE will combine data from KarstINDIC (e.g. type and thickness of the overburden) with data from KarstALEA (e.g. position of preferred karst development) and KARSYS (mainly the head data) in order to produce qualitative maps of potential ground collapses. A first example is presented on Figure 7. Further data will need to be collected and combined to refine the reliability of the map. For more quantitative results, the application of KarstFLOWSIM (Figure 6) is necessary, especially concerning groundwater heads and their variations in the aquifer, which is a key-factor for triggering karst collapses. Karst collapse hazard maps have been produced, but the approach needs to be refined.

\section{Examples of Karst Toolbox Applications Flood hazard assessment in the Beuchire catchment area}

The city of Porrentruy has expanded around a perennial karst spring (Beuchire spring). The city is occasionally flooded by water coming from an overflow spring (Creugenat) located several kilometers upstream along a dry valley. This valley, which becomes active only during high flow conditions, is settled by several villages. Authorities must provide a flood hazard map with indications about the probability, position, and intensity of potential flooding. No surface perennial rivers or streams are present in this region. One part of the dry valley becomes active during high water periods, but the part of the valley, which floods, depends on the intensity of the rainfall. The catchment area feeding the springs (perennial and overflow) was not well known. Hydrologists were asked to produce a map with the respective indications, but they were disappointed when they realized there was no river or mapped catchment area, i.e. no information for feeding the models used for making the assessment.

We used KARSYS to delineate the catchment area as well as the extension of the groundwater body (phreatic zone) present in this catchment. First it was made for 


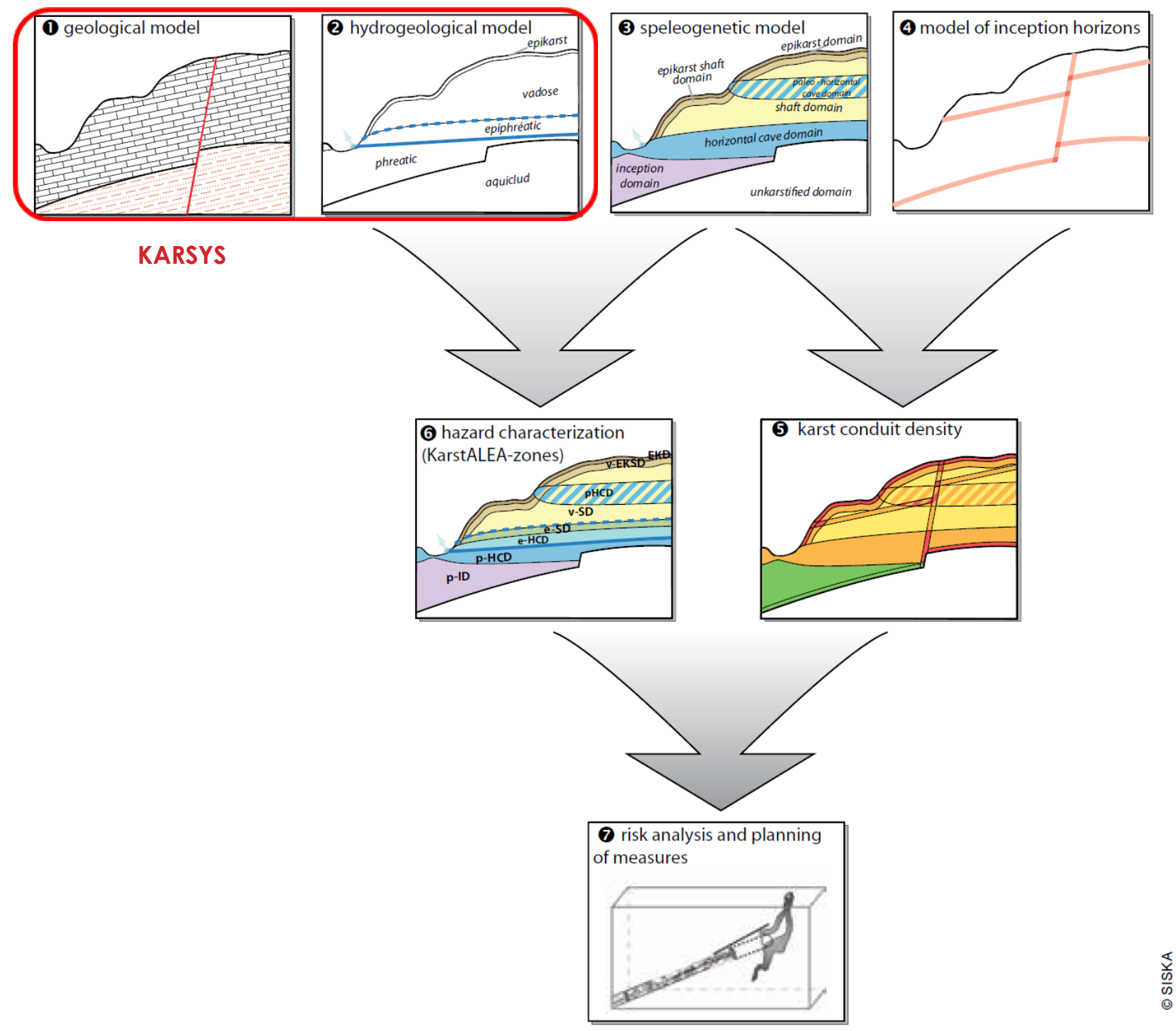

Figure 4. The 7 successive steps of the KarstALEA method as developed for a tunnel project. Four 3D models of the massif are constructed in steps 1 to 4 ( 1 and 2 being the KARSYS models). In steps 5 and 6 zones with the highest expected densities of karst conduits and their characteristics are interpreted. In step 7 hazards, risks, and mitigation measures are identified and discussed between the tunnel geologist and the tunnel engineer.

low water conditions. Next, and thanks to existing data of heads in caves, we assessed the extension under high flow conditions (within the range of measured data). Those analyses provided evidences that the catchment area changes depending on conditions. During low water conditions, two groundwater bodies are separated by an impervious anticline. The rising of groundwater during high water conditions activates an overflow over this anticline, bringing water from the nearby catchment towards the Beuchire catchment area. For assessing heads and discharge rates in the downstream part of the catchment, where the flood hazard map was required, we linked recharge coming from the assessed catchment area with the region enclosing the outlets. To simulate those conditions, recharge and flow paths through the aquifer had to be assessed. A recharge model was calibrated first. For the routing, a network of pipes draining the whole aquifer had to be generated somehow. Considering the data available (flow at springs and groundwater heads in different caves in the downstream part of the system), we decided to simulate flow and heads in this part using a pipe-flow modelling software. After a few 


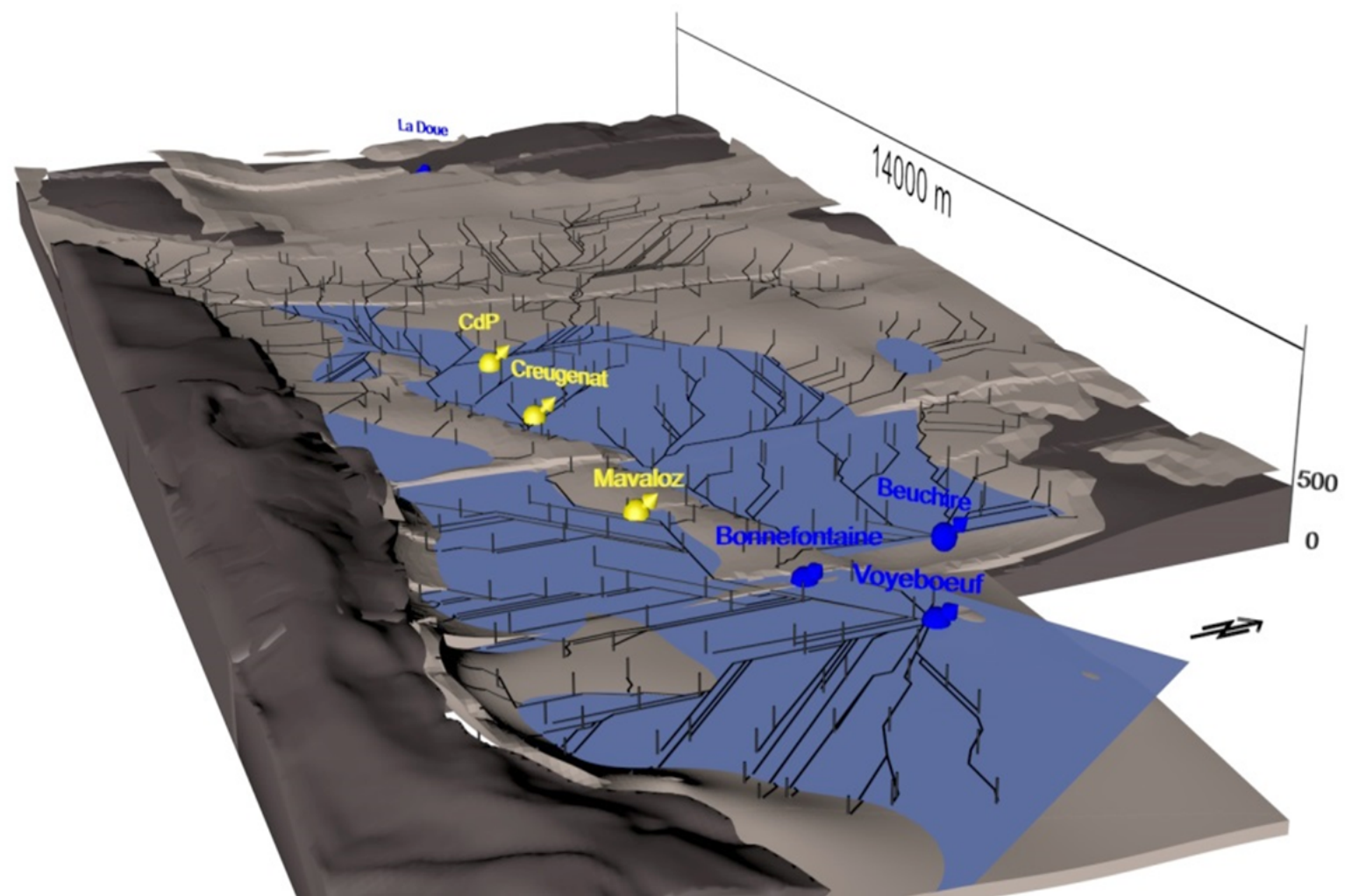

Figure 5. Example of a conduit network generated with KarstNETGEN based on KARSYS and KarstALEA results.

Adjust:

- Autochtonous \& Allochtonous sub-catchments contribution - conduits diameter, additional conduits, etc.
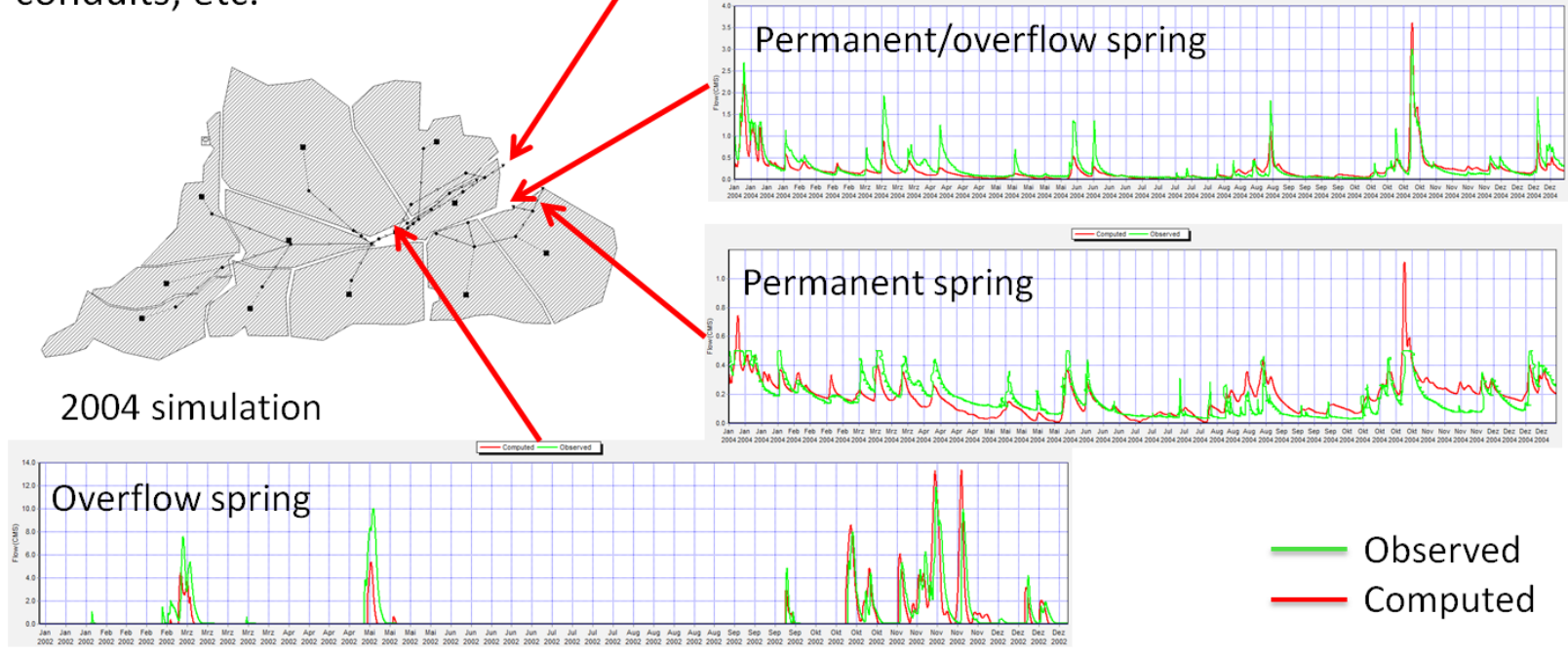

Observed Computed

Figure 6. Example of hydrographs of four springs simulated with KarstFLOWSIM ("Permanent spring" means "perennial spring"). 


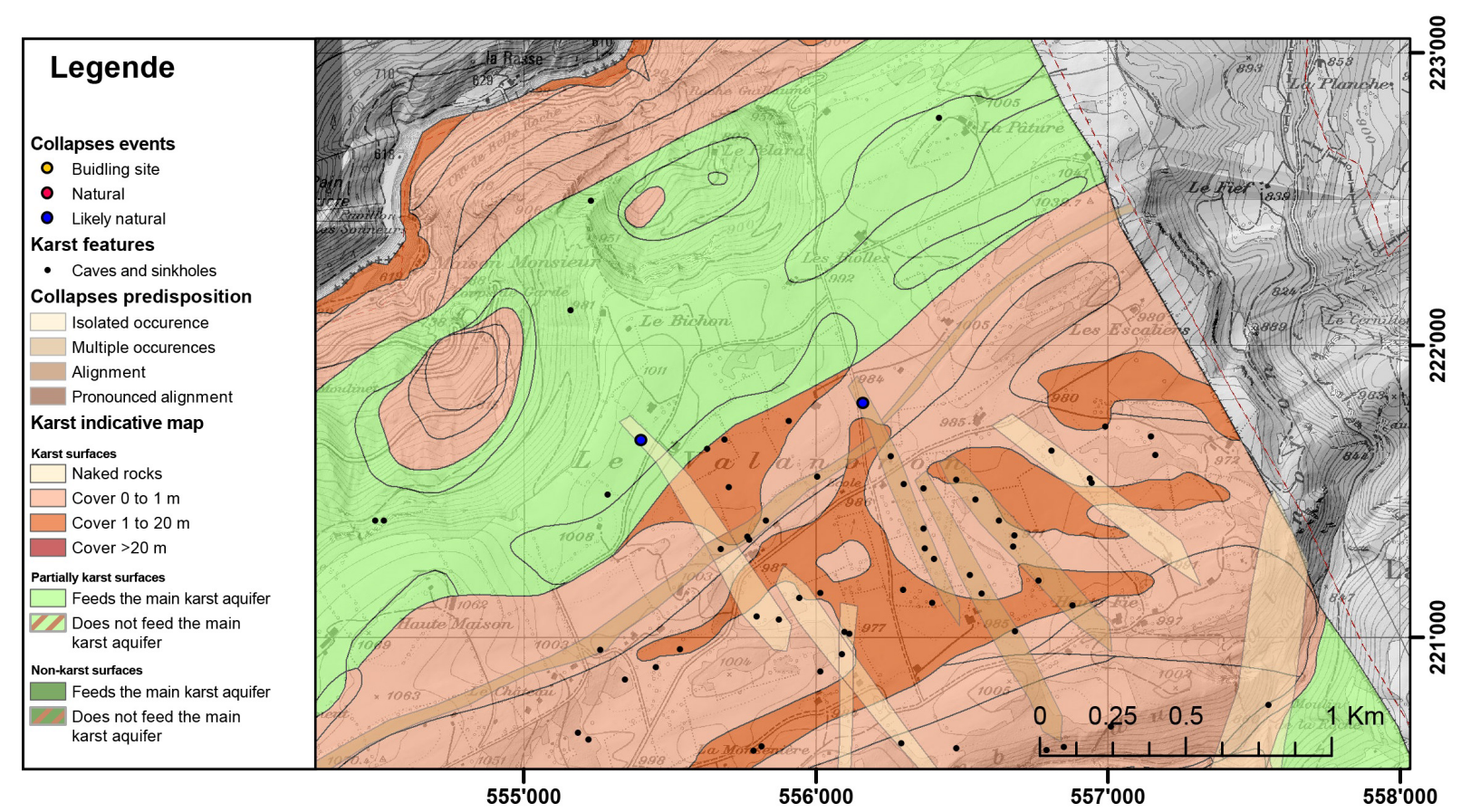

Figure 7. Example of karst hazard map produced with conceptual KarstCOLLPASE module principles.

High Creugenat event ( annual)

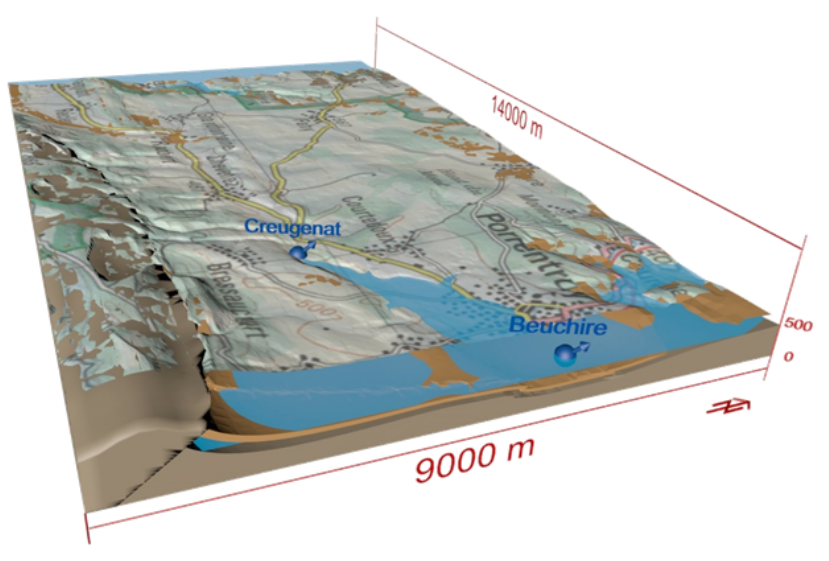

High CdP event ( $\sim 30$ years)

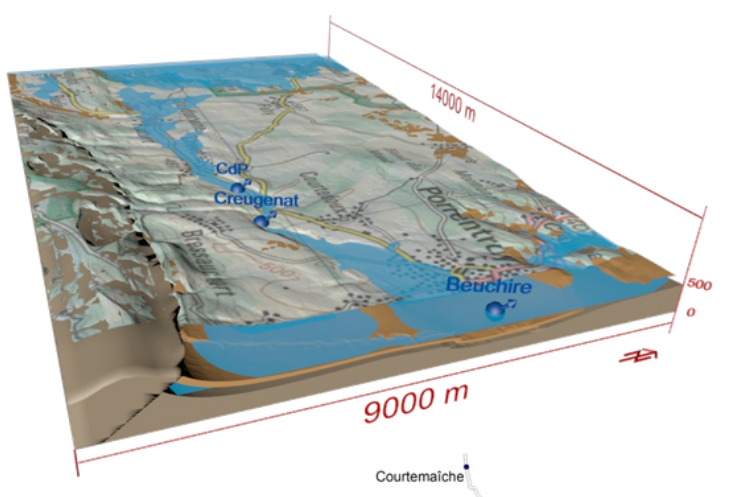

\section{0 years event}

\section{Exfiltration zones}
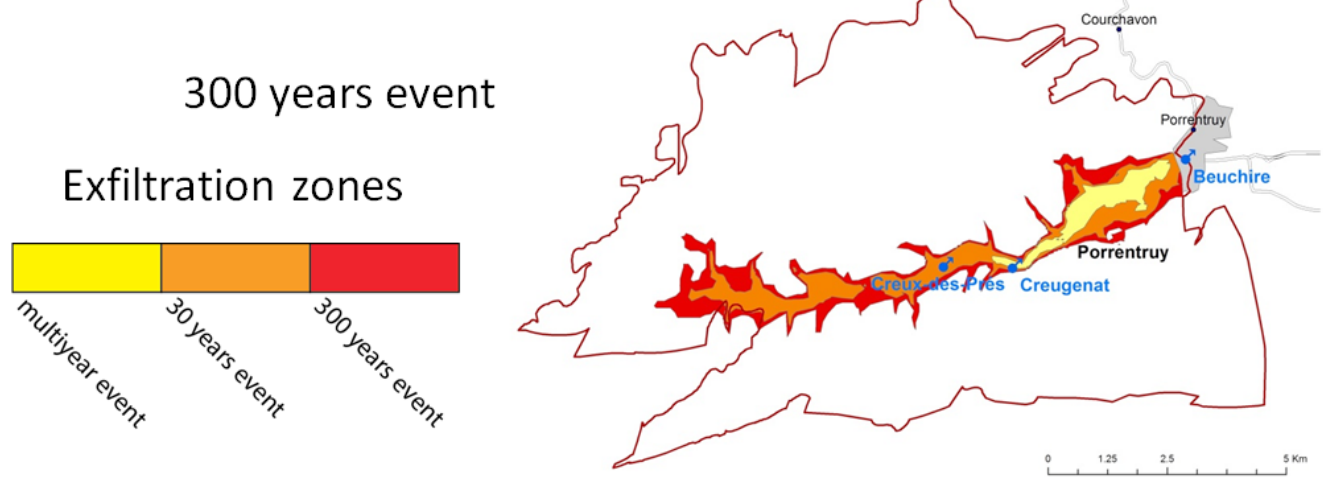

Figure 8. Map of flood hazards in the Beuchire catchment area (JU, Switzerland). Top left: areas vulnerable to floods during an usual overflow event of the Creugenat spring. Top right: areas vulnerable to floods during an overflow event of the Creugenat spring with a return period of 30 years. 
iterations the modelled conduit network provided a good fit with groundwater observed heads and flow rates. Caves explored and surveyed by cavers were another set of information. For the upstream part we developed a karst channel network generator, based on results of KarstALEA and KARSYS. The complete network could thus be generated, linking all regions of the catchment area to the four outlets of the system (Figure 5). The complete pipe network was included into the pipeflow model, which was calibrated by adjusting the pipe network topology and pipe size, until it reasonably reproduces discharge time series of the respective springs and heads measured at a few locations in the karst channels.

Extreme rainfall scenarios were discussed with engineers and introduced into the model, which provided an idea of how high the groundwater table could rise, where it would breach land-surface, and how much water is expected to flow at those locations. Results of that modelling are shown in Figure 8.

This case study helped us to develop and refine our tools and improve ways to connect one to another.

\section{Ground collapse hazard in Northern Switzerland}

The project associated with this case-study is not finished. Names and precise location are therefore not provided. The goal of the project is to answer the following questions: Where could piles of a bridge and water injection plants be placed on order to avoid or minimize the triggering of collapse sinkholes, which are known to frequently occur in the region?

The geology of the (flat) region is as follows: A series of unconsolidated rocks with a thickness ranging between 10 to 45 meters laying on top of a highly karstified limestone, presumably of hypogenic origin, containing a high density of voids. The analysis of existing data showed that collapse sinkholes are produced mainly by piping of unconsolidated sediment into the karst voids, producing voids in the unconsolidated sediment, which then migrate upwards to the surface as the sediment ravels. The piping is strongly related to hydrologic conditions. In this region the groundwater potentiometric surface is located and fluctuates mainly within the unconsolidated rock.

The application of KARSYS with few adjustments made it possible to show regions where groundwater does not reach the unconsolidated sediment, i.e. where the danger of collapse sinkholes is lower, and to see where piles could be placed, and how identified dangers could be mitigated.

\section{Discussion}

The methods of the Karst Toolbox are applicable to assess most applied problems in karst, including natural hazards such as floods and collapse sinkholes. Once one method is applied (usually KARSYS first) for one problem, the other methods which provides very useful information for mitigating problems.

Karst Toolbox has limitations. The tools are developed following demands and problems specific to central Europe, i.e. temperate mountainous regions. They might be less efficient or even not applicable in other karst terrains (e.g. lowland karst or hypogenic karst areas). Adjustments and extensions for other terrains should be developed.

Another aspect is that results may appear to be precise and accurate. However, the models are only as precise as the data used to make them. This must never be forgotten. A possible future addition may include tools for uncertainty assessment. This is however a very challenging task. Nevertheless, along the construction of the models, the modeler identifies aspects which are the most unreliable and can target complimentary investigations (e.g. geophysical survey) in places where they are really needed. If all or most existing data have been introduced in the model, it can by a very effective tool to assess if the level of detail of the existing data is sufficient for addressing the question. Another advantage is any new data is directly integrated in context of existing data (e.g. a groundwater level can be directly viewed in the aquifer, confined or artesian.

Another aspect is most results produced by these tools include 3D visualizations of conceptual model which hydrogeologists usually try to express through maps and profiles. Showing them explicitly is a strong advantage for explaining to decision makers or even to the public. A lot of words and time are saved by showing a 3D model which visually explains the underground flow conditions. The tools also help the modeler refine ideas, and raise new unexpected ones. Finally the Karst Toolbox enables other hydrogeologists to criticize the model if it does not fit their own ideas.

\section{Conclusion}

In this paper we briefly sketched a way to chain and combine models and approaches to cope with practical issues in karst. Too often investigations are according to what an investigator can do, rather than the most 
effective way to address the question. Our experience is it is very effective to gather all existing data into our well-structured database, visualize in $3 \mathrm{D}$ and target further investigations based on this explicit compilation. With some practice, this work can be achieved with reasonable effort (and money) and it increases objectivity and decreases liability of the assessments. The communication of the principles, assumptions, and results is strongly improved.

With remote sensing and new techniques a lot of new data are becoming available and being developed for improving our knowledge of the underground. Computers are no longer a limitation to managing these data. The main limitation is the absence of efficient tools to make this compilation work. GIS helps, but is essentially $2 \mathrm{D}$ (or 2.5D), which is a strong limitation for hydrogeology. The Karst Toolbox is an attempt to develop such tools for karst, which could be applied in other hydrogeological contexts.

The sketched Karst Toolbox is applicable at our place. Making it available outside is a difficult task because our whole know-how must be merged into user-friendly tools, which is a considerable piece of work! Visual KARSYS is now being developed with this purpose. That effort started in 2016 and will continue until 2019. This web application will explain and provide all the necessary tools for any user, to apply KARSYS for making his own model. KARSYS will be available by 2019, and further pieces of the Karst Toolbox will be progressively implemented, depending on demand for applications.

\section{References}

Doerfliger N, Jeannin P-Y, Zwahlen F. 1999. Water vulnerability assessment in karst environments: a new method of defining protection areas using a multi-attribute approach and GIS tools (EPIK method). Environmental Geology 39(2): 165-176.

Filipponi M, Schmassmann S, Jeannin P-Y, Parriaux A 2012. KarstALEA: Wegleitung zur Prognose von Karstspezifischen Gefahren im Untertagbau. Bundesamt für Strassen ASTRA.

Jeannin PY, Malard A, Rickerl D, Weber E 2015. Assessing karst-hydraulic hazards in tunneling - the Brunnmühle spring system - Bernese Jura, Switzerland. Environmental Earth Sciences, 74(12): 7655-7670.

Malard A, Jeannin P-Y, Vouillamoz J, Weber E 2015. An integrated approach for catchment delineation and conduit-network modeling in karst aquifers: application to a site in the Swiss tabular Jura. Hydrogeology Journal, 23(7): 1341-1357.
Vouillamoz J, Malard A, Schwab-Rouge G, Weber E, Jeannin PY 2013. Mapping flood related hazards in karst using KARSYS approach. Application to the Beuchire-Creugenat karst system (JU, Switzerland). Proceedings of the 13th Multidisciplinary Conference on Sinkholes and the Engineering and Environmental Impacts of Karst, held in Carlsbad, New Mexico, May 06-10, 2013. 333-342.

Waltham T, Bell F, Culshaw M 2005. Sinkholes and subsidence: karst and cavernous rocks in engineering and construction. Springer Praxis, Series: Geophysical Sciences. 